\title{
Towards larger volume reduction of nodular goitres by radioiodine therapy: a role for pretreatment with recombinant human thyrotropin?
}

\author{
Dyde A. Huysmans*, Willy-Anne Nieuwlaat† and \\ Ad R. Hermus† \\ *Department of Nuclear Medicine, Catharina Hospital, \\ Eindhoven and $\uparrow$ Department of Endocrinology, University \\ Medical Center, Nijmegen, the Netherlands
}

(Received 4 August 2003; accepted 14 November 2003)

In the last two decades it has been demonstrated that radioiodine $\left({ }^{131} \mathrm{I}\right)$ is an effective therapy for thyroid volume reduction in patients with toxic and nontoxic nodular goitre. In these patients, ${ }^{131}$ I treatment leads to a significant decrease in goitre size. In most patients compressive symptoms improve as well. The decrease in compressive symptoms is accompanied by significant tracheal widening and improvement of respiratory function (for review see Hegedüs et al., 2003).

${ }^{131}$ I treatment is especially attractive in elderly patients who have a high operative risk and in those who refuse surgery. However, in patients with nontoxic, nodular goitre thyroid radioactive iodide uptake (RAIU) is usually rather low, especially in areas with a high iodine intake. As a result, high doses of ${ }^{131} \mathrm{I}$ are often needed for thyroid volume reduction, causing a relatively high radiation burden to extrathyroidal organs (Huysmans et al., 1996). Therefore, it is of interest to explore strategies to enhance RAIU in these patients. In the last decade recombinant human thyrotropin (rhTSH) has become available for diagnostic use in patients with differentiated thyroid cancer. It has been shown that rhTSH stimulates RAIU in thyroid remnants and thyroid cancer tissue (Ladenson et al., 1997; Haugen et al., 1999). Recently, we reported that rhTSH stimulates RAIU also in patients with nodular goitre: the administration of a single, low dose of 0.01 or $0.03 \mathrm{mg}$ rhTSH doubled 24-h RAIU in these patients (Huysmans et al., 2000). Pretreatment with rhTSH also caused a more homogeneous distribution of radioiodine on the thyroid scintigrams of nodular goitres by stimulating radioiodide uptake in relatively cold areas more than in relatively hot areas, especially in patients with a low baseline serum TSH level (Nieuwlaat et al., 2001). These observations suggest that administration of rhTSH before ${ }^{131}$ I therapy for volume reduction of nodular goitre may allow treatment with lower doses of ${ }^{131}$ I without diminishing the radiationabsorbed dose in the thyroid and the efficacy of this mode of therapy. Indeed, pretreatment with a single, low dose of 0.01 or
$0.03 \mathrm{mg}$ rhTSH allowed approximately $50-60 \%$ reduction of the therapeutic dose of radioiodine without compromising the efficacy of thyroid volume reduction (Nieuwlaat et al., 2003). As the radiation burden of radioiodine therapy to extrathyroidal organs is directly related to the administered ${ }^{131} \mathrm{I}$ dose (Huysmans et al., 1996), such a dose reduction may render radioiodine therapy more attractive for younger patients and may allow for more patients to be treated on an out-patient basis.

A major drawback of radioiodine therapy for nodular goitre (with ${ }^{131} \mathrm{I}$ doses aimed at approximately $100-150 \mu \mathrm{Ci}$ retained per gram of thyroid tissue at $24 \mathrm{~h}$ ) is that mean thyroid volume reduction is not greater than approximately $40 \%$ after 1 year, and 50-60\% after 3-5 years (for review see Hegedüs et al., 2003). Moreover, not all patients respond. Preliminary data by Le Moli et al. (1999) suggest that goitre reduction can be augmented by increasing the radiation-absorbed dose in the thyroid. Such an increase can be achieved by simply enlarging the administered dose of radioiodine, but this will further increase the radiation burden to extrathyroidal organs. Alternatively, it should be possible to increase the radiation-absorbed dose in the thyroid without increasing the administered dose of radioiodine, by stimulating RAIU using pretreatment with rhTSH.

In this issue of Clinical Endocrinology, Silva et al. (2004) report a study in which 34 patients with large, nodular goitres (22 were subclinically hyperthyroid and seven overtly hyperthyroid) were randomized to radioiodine therapy alone or to radioiodine therapy in comparable doses but with pretreatment with a relatively high dose of rhTSH $(0.45 \mathrm{mg})$, given $24 \mathrm{~h}$ before radioiodine administration. Patients pretreated with rhTSH had a significantly larger thyroid volume reduction after 1 year $(58 \pm 13 \%$; mean $\pm \mathrm{SD}$ ) than patients given radioiodine without rhTSH pretreatment ( $40 \pm 12 \%)$.

From data provided in Tables 1 and 2 of their report, we calculated the dose retained in the thyroid at $24 \mathrm{~h}$ for individual patients in both groups. This parameter was considerably higher in the rhTSH-pretreated patients $(191 \pm 75 \mu \mathrm{Ci} / \mathrm{g}$ of thyroid tissue) than in the patients not pretreated with rhTSH $(73 \pm 22$ $\mu \mathrm{Ci} / \mathrm{g})$. It seems likely that the higher thyroid volume reduction in the rhTSH-pretreated group can be explained by the higher retention of radioiodine in the thyroid. An alternative explanation is that pretreatment with rhTSH improves thyroid volume reduction by causing a more homogeneous distribution of radioiodine within the thyroid, especially increasing the uptake of radioiodine in relatively cold areas (Nieuwlaat et al., 2001). 
It may be anticipated that a higher dose of radioiodine retained in the thyroid will be accompanied by more severe early adverse effects due to radiation-induced thyroiditis and oesophagitis. Indeed, in comparison with patients not pretreated with $\mathrm{rhTSH}$, rhTSH-pretreated patients had a higher incidence of pain in the thyroid region (52\% vs. 23\%), complaints due to oesophagitis (17\% vs. 11\%) and weight loss (65\% vs. 52\%).

Another consequence of thyroiditis is acute enlargement of the thyroid gland with (further) compression of the trachea. For radioiodine doses aimed at approximately $100-150 \mu \mathrm{Ci}$ retained per gram of thyroid tissue at $24 \mathrm{~h}$, increases in thyroid volume 1 week after radioiodine therapy up to $25 \%$ have been found (Nygaard et al., 1994; Bonnema et al., 1999; Nieuwlaat et al., 2003). Silva et al. (2004) did not quantify thyroid volume changes in the first period after radioiodine therapy. Therefore, it remains to be investigated whether the larger ${ }^{131} \mathrm{I}$ doses retained in the thyroid as used by Silva et al. (2003) cause larger increases in thyroid volume in the first period after radioiodine treatment.

Mild increases in serum thyroid hormone levels due to radiationinduced thyroiditis are commonly seen in the first weeks after radioiodine treatment of nodular goitre, with maximum levels reached at approximately 2 weeks after therapy (Nygaard et al., 1994). It has also been demonstrated that administration of low doses of rhTSH $(0.01$ or $0.03 \mathrm{mg})$ in patients with nodular goitre results in mild increases in serum thyroid hormone levels, with maximum levels reached at 1-4 days after administration of rhTSH (Huysmans et al., 2000). It may be anticipated that pretreatment with a relatively high dose of rhTSH followed by a full dose of radioiodine, leading to a high radiation-absorbed dose in the thyroid, will result in larger increases in serum thyroid hormone levels. Indeed, peak FT4 levels reached in the rhTSHpretreated patients studied by Silva et al. (2004) were much higher than those in the patients treated with radioiodine alone $(59 \pm 22$ vs. $24 \pm 7 \mathrm{pmol} / 1)$, despite a low-iodine diet in all patients and methimazole pretreatment in the seven overtly hyperthyroid patients. The highest FT4 levels were reached already at 1-3 days after radioiodine therapy, suggesting that rhTSH administration was the most important cause of the rise. Fortunately, no hyperthyroid symptoms or worsening of heart diseases were observed. The authors give three possible explanations: the rise in thyroid hormone levels was of short duration, most patients had cardiac medications, and all patients were confined to their beds for 59 days after radioiodine therapy.

A late adverse effect of radioiodine treatment of nodular goitre is development of hypothyroidism. Probably related to the higher radioiodine dose retained in the thyroid, Silva et al. (2004) found that hypothyroidism 1 year after radioiodine therapy was more frequent in the rhTSH-pretreated patients than in the patients not pretreated with rhTSH (65\% vs. 21\%).

The study of Silva et al. (2004) is the first to show that the efficacy of radioiodine therapy of nodular goitres can be improved by pretreatment with rhTSH. However, conclusions are based on small numbers of patients and both toxic (four of them had used amiodarone) and nontoxic patients were included. Moreover, no attempt was made to calculate precisely the radioiodine doses to be administered (radioiodine doses were based on a rather simple algorithm with estimated thyroid volume as the only parameter).

Before rhTSH can be advised as an adjunct to improve the efficacy of radioiodine therapy in nodular goitre, further studies are needed. First, it has to be determined in a formal dose-response study which dose of rhTSH is optimal for this purpose. Such a dose should stimulate RAIU considerably, but should not cause unacceptable rises in serum thyroid hormone levels. Then, radioiodine therapy with and without pretreatment with that particular dose of rhTSH should be investigated in randomized studies. Such studies should look carefully at dose-response relationships with respect to efficacy and adverse effects. Given the heterogeneity of nodular goitres, large groups of patients will be needed.

\section{References}

Bonnema, S.J., Bertelsen, H., Mortensen, J., Andersen, P.B., Knudsen, D.U., Bastholt, L. \& Hegedüs, L. (1999) The feasibility of high dose iodine 131 treatment as an alternative to surgery in patients with a very large goiter: effect on thyroid function and size and pulmonary function. Journal of Clinical Endocrinology and Metabolism, 84, 3636-3641.

Haugen, B.R., Pacini, F., Reiners, C., Schlumberger, M., Ladenson, P.W., Sherman, S.I., Cooper, D.S., Graham, K.E., Braverman, L.E., Skarulis, M.C., Davies, T.F., DeGroot, L.J., Mazzaferri, E.L., Daniels, G.H., Ross, D.S., Luster, M., Samuels, M.H., Becker, D.V., Maxon, H.R., Cavalieri, R.R., Spencer, C.A., McEllin, K., Weintraub, B.D. \& Ridgway, E.C. (1999) A comparison of recombinant human thyrotropin and thyroid hormone withdrawal for the detection of thyroid remnant or cancer. Journal of Clinical Endocrinology and Metabolism, 84, 3877-3885.

Hegedüs, L., Bonnema, S.J. \& Bennedbæk, F.N. (2003) Management of simple nodular goiter: current status and future perspectives. Endocrine Reviews, 24, 102-132.

Huysmans, D.A.K.C., Buijs, W.C.A.M., van de Ven, M.T.P., van den Broek, W.J.M., Kloppenborg, P.W.C., Hermus, A.R.M.M. \& Corstens, F.H.M. (1996) Dosimetry and risk estimates of radioiodine therapy for large, multinodular goiters. Journal of Nuclear Medicine, 37, 2072 2079.

Huysmans, D.A.K.C., Nieuwlaat, W.-A., Erdtsieck, R.J., Schellekens, A.P., Bus, J.W., Bravenboer, B. \& Hermus, A.R. (2000) Administration of a single low dose of recombinant human thyrotropin significantly enhances thyroid radioiodide uptake in nontoxic nodular goiter. Journal of Clinical Endocrinology and Metabolism, 85, 3592-3596.

Ladenson, P.W., Braverman, L.E., Mazzaferri, E.L., Brucker-Davis, F., Cooper, D.S., Garber, J.R., Wondisford, F.E., Davies, T.F., DeGroot, L.J., Daniels, G.H., Ross, D.S. \& Weintraub, B.D. (1997) Comparison of administration of recombinant human thyrotropin with withdrawal of thyroid hormone for radioactive iodine scanning in patients with thyroid carcinoma. New England Journal of Medicine, 337, 888 896.

Le Moli, R., Wesche, M.F.T., Tiel-van Buul, M.M.C. \& Wiersinga, W.M. 
(1999) Determinants of longterm outcome of radioiodine therapy of sporadic non-toxic goitre. Clinical Endocrinology, 50, 783-789.

Nieuwlaat, W.-A., Hermus, A.R., Sivro-Prndelj, F., Corstens, F.H. \& Huysmans, D.A. (2001) Pretreatment with recombinant human TSH changes the regional distribution of radioiodine on thyroid scintigrams of nodular goiters. Journal of Clinical Endocrinology and Metabolism, 86, 5330-5336.

Nieuwlaat, W.-A., Huysmans, D.A., van den Bosch, H.C., Sweep, C.G., Ross, H.A., Corstens, F.H. \& Hermus, A.R. (2003) Pretreatment with a single, low dose of recombinant human thyrotropin allows dose reduction of radioiodine therapy in patients with nodular goiter. Journal of Clinical Endocrinology and Metabolism, 88, 3121-3129.

Nygaard, B., Faber, J. \& Hegedüs, L. (1994) Acute changes in thyroid volume and function following ${ }^{131} \mathrm{I}$ therapy of multinodular goitre. Clinical Endocrinology, 41, 715-718.

Silva, M.N.C., Rubió, I.G.S., Romão, R., Gebrin, E.M.M.S., Buchpiguel, C., Tomimori, E., Camargo, R., Cardia, M.S. \& Medeiros-Neto, G. (2004) Administration of a single dose of recombinant human thyrotropin enhances the efficacy of the radioiodine treatment of large compressive multinodular goitres. Clinical Endocrinology 60, 300-308. 